
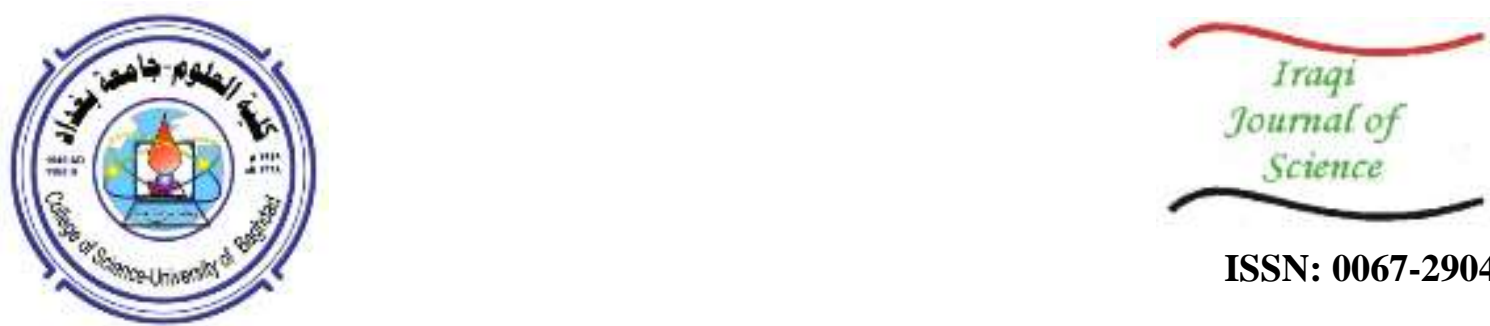

ISSN: 0067-2904

\title{
Incorporation of Palm Fiber to Enhance the Mechanical Properties of Epoxy
}

\author{
Samah M. Hussein \\ Department of Applied Science, University of Technology, Baghdad, Iraq
}

\author{
Received: 13/11/2019 Accepted: 3/4/2020
}

\begin{abstract}
In the recent years, the work in composite industry needed new ecofriendly resources to improve the original properties of current materials. Many researches attempted to find alternative additives to be used with the current systems which provide a new material that is environmentally friendly and has better performance than the synthetic counterparts. This paper presents the study of mechanical characteristics, including bending, impact, tensile and hardness tests, of date palm fiber (DPF)/ epoxy composite. The composite plate was constructed by hand-layup technique. The filler content values (wt \%) were 5\%, 10\%, 15\% and 20\%. Young's modulus, impact strength and hardness were shown to be increased with increasing fiber content. Tensile strength was increased only by using $5 \%$ and $10 \%$, where as it was decreased by increasing fiber content.
\end{abstract}

Keywords: Epoxy, Date palm fiber, hand-layup technique, young's modulus, impact strength, tensile strength.

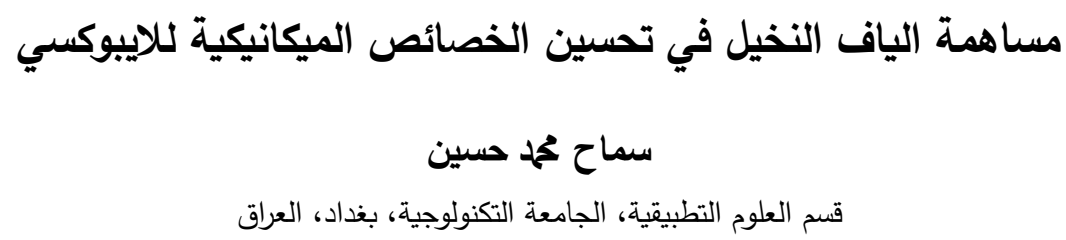

$$
\begin{aligned}
& \text { الخلاصة } \\
& \text { في السنوات الأخيرة ، احتاج العمل لصناعة المواد المتراكبة إلى استخدام مصادر جديدة صديقة للبيئة } \\
& \text { لتحسين الخصائص الأصلية للمواد الحالية. العديد من الأبحاث عملت على إيجاد مادة مضافة العادية بديلة العادية }
\end{aligned}
$$

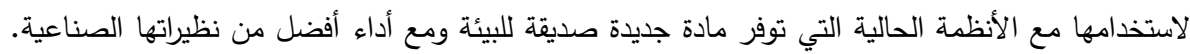

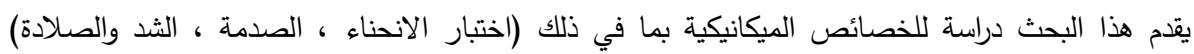

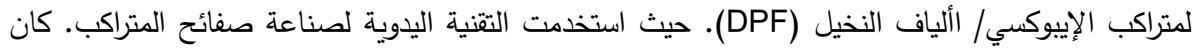

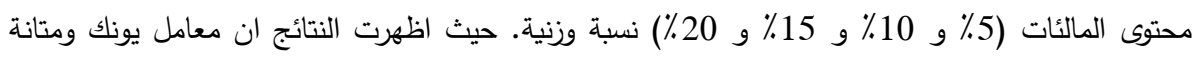

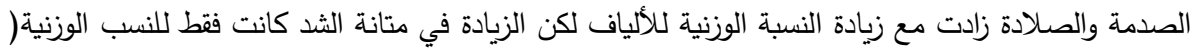

$$
\begin{aligned}
& 5 \text { \% و } 10 \text { \% )باستثاء النسب( } 15 \text { \% و } 20 \text { \%) الثي اظهرت النقصان. }
\end{aligned}
$$

\section{Introduction}

Composites are proven to be cost-effective materials, while the additional current goal is to use environmentally friendly materials. As a result of the efforts of scientists and engineers, techniques were devised that are currently used in the manufacture of composites with economic importance [1,

*Email: 100054@uotechnology.edu.iq 
2]. At the present time and due to ecological laws and regulations, the removal of composite components (plastics, ceramics, artificial fibers, etc.) is becoming a serious problem for several industries. Recently, there is growing demand on polymeric composites filled with natural fillers (fibers or powders) to be used in a wide range of industrial and medical applications, due to many reasons such as good environmental properties, affordability, and ease of manufacturing in comparison with traditional artificial additives [3-6].

Previous researches proved the high benefit of natural fibers with organic matrices due to their greater strength and toughness than those of the matrix materials. Moreover, lignocellulose natural fibers possess many favorable properties, since they are cheap, strong, light in weight, abundant and renewable. In the last decade, natural fibers were utilized as a common resource in manufacturing lowcost composite materials. On the other side, the lack of good adhesion between matrices and used natural fibers was an obstacle. Practically, natural fibers possess a high moisture sorption capacity which affects adhesion with a hydrophobic matrix, which accelerates the composite failure due to material degradation and loss of stiffness [7].

Natural fibers are described as a better replacement to the conventional synthetic fibers such as Kevlar, glass and carbon. Natural fibers have special physical, mechanical, and chemical properties depending upon the cellulosic content that varies from a fiber to another [8]. The fiber-matrix interface properties are essential in the macroscopic mechanical aspects. Both physical and chemical treatments can be used to enhance this interface. Also, the efficiency of fibers varies depending on the material and the method used [9].

Date palm trees are found abundantly in the Middle East countries compared to other regions. Many research works have been carried out for developing composites using date palm fronds and fibers [10, 11]. These fibers have filament textures with distinct properties, such as low costs, durability, lightweight, tension possibility and relative strength against wear. Thus, palm fibers are possible to use as an alternative low cost natural material for soil reinforcement [12].

Composites with natural fiber additives are the most common materials used in different sectors of engineering, because of the high definite strength and toughness. Using this additive is considered essential to obtain a material with high mechanical properties. Fibers mechanical properties present a higher performance than that of the polymer matrix. Therefore, the load is transferred from the matrix to the reinforced fiber. Currently, many kinds of natural fibers are utilized as additives in preparing composite materials, such as pineapple, coir, sisal and jute. Several features of these fibers such as high quality, economical acceptance, and low density, make more desired to fabricate composites. Oppositely, these fibers are considered flexible, with variable diameters along the length of each fiber, while also having coarse surfaces. Also, they are sensitive to both temperature and moisture and generally have a multi-cross section [13].

The date palm tree is a member of the palm tree family (phoenix Dactylifera), which is very commonly found in the country of the current study (Iraq) as well as in the Canary Islands, Pakistan, India, Northern Africa, and California. More than 100 million date palm trees are distributed in different countries, while the average age for these trees is estimated to be more than 100 years [14].

The reinforcement of polymers plays an essential role in the enhancement of the mechanical properties of high performance materials. Hence, some of mechanical characteristics of epoxy composites were studied in order to improve engineering materials for industrial uses such as dashboard, car seat, and interior parts of automobile. For these purposes, laminate composite samples were manufactured from date palm fibers (DPF) with epoxy resin as a matrix. Also, the specific mechanical properties (bending, impact, tensile and hardness) of the prepared composites were assessed.

\section{MATERIALS AND METHODS}

\section{Materials}

Epoxy resin (type Sikadur-52) supplied by Shenzhen Zhengdasheng Chemical Co., Ltd. was used in this research; it is a liquid with low viscosity and capable to be transformed to solid state by adding a solution (Metaphenylene Diamine, MPDA) as a hardener. This hardener is a light liquid with semitransparent color (pale yellow). The ratio of this hardener to the epoxy was about 1:2.

The stem of date palm tree was shielded with a mesh consisted of a natural woven mat made of specific crossed fibers of different diameters (Figure-1). Conventionally, these mats are usually used to make ropes and baskets in many parts of the world after being removed from the trees and manually cleaned. The chemical components of the mentioned woven mat are given in Table-1. 


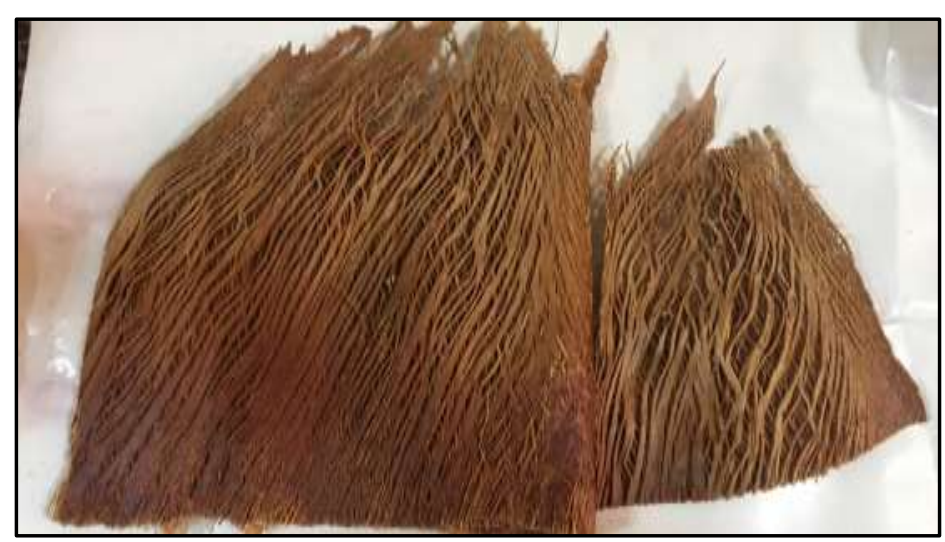

Figure 1-Date palm textile.

Table 1-Chemical composition of DPF [15]

\begin{tabular}{cccc}
\hline $\begin{array}{c}\text { Cellulose } \\
\text { Wt. }(\%)\end{array}$ & $\begin{array}{c}\text { Lignin } \\
\text { Wt. }(\%)\end{array}$ & $\begin{array}{c}\text { Hemicelluloses } \\
\text { Wt. }(\%)\end{array}$ & $\begin{array}{c}\text { Moisture content } \\
\text { Wt. }(\%)\end{array}$ \\
\hline 46 & $\mathbf{2 0}$ & $\mathbf{2 8}$ & $\mathbf{5}$ \\
\hline
\end{tabular}

\section{Preparation of the composites}

In the beginning, the DPFs were subjected to chemical treatment; firstly, the fibers were immersed in water containing $6 \% \mathrm{NaOH}$ solution for about 3 hours. Then, the fibers were dried in the oven at $60 \mathrm{C}^{\mathrm{o}}$ for 2 hours. The fibers were left for 24 hours to dry at room temperature before being used. Chemical treatment was used to improve the compatibility bonding between the fibers and matrix. Hand lay -up method was used to prepare the samples by using epoxy as a matrix and DPFs as additives with wt $\%$ values of $5 \%, 10 \%, 15 \%$ and $20 \%$.

Epoxy and hardener were mixed in a container and stirred well for 3-5 minutes.

The composites were prepared according to the following procedure:

- A clean glass with dimensions of $16^{*} 10^{*} 0.6 \mathrm{~cm}$ was used for casting the sheets of the composites (Figure-2a). A polymer sheet (fablone) was fixed on the inner mould faces before casting to facilitate the release of the casting composites and to ensure having smooth faces.

- Upon adding the fibers, they were cut and aligned in the mould (fig. $2 b$ ) before pouring the blend (epoxy and hardener). The fibers were stacked until the desired thickness was obtained. The thickness of samples was about 6-6.5 mm, where one layer of fiber was used to reinforce the ratios of $5 \%$ and $10 \%$, and two layers to reinforce the ratios of $15 \%$ and $20 \%$.

- In order to apply a constant load on the casting sheet to release voids, bubbles, and to have a specified thickness and smooth face, covering the mould represented a necessary process in the preparation procedure.

- The molding sheet was left inside the mould at room temperature for about $48 \mathrm{hr}$.

- For the post-cure stage of all samples, the casting sheet, after solidification, was released from the mould and placed in an oven at $55^{\circ} \mathrm{C}$ for $3 \mathrm{hr}$.

- $\quad$ According to the ASTM test, all samples were cut and prepared for the tests.

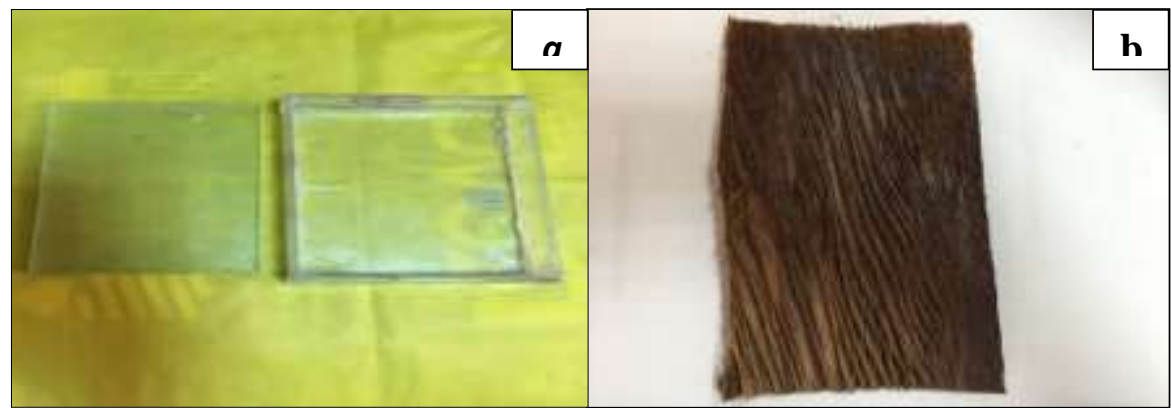

Figure 2-a-photographic image of a cast mould of composites- DPF Sheet 


\section{Measurements}

\section{Three-point bending test}

The modulus of elasticity is the main magnitude that is measured in the test. This value measures materials resistance to elastic deformation; the stress $(\sigma)$ is related to the strain $(\varepsilon)$ within linear elastic deformation of materials by Young's modulus (E) (Hook's law).The bending test system (Phywe) is used to determine the modulus of elasticity. The distance between the supports was fixed at $80 \mathrm{~mm}$. The following equations were used to determine Young's modulus of the specimens [16, 17].

$$
E=\frac{m g L 3}{48 I s}
$$

$I=\frac{b d 3}{12}$

E is Young's modulus $\left(\mathrm{N} / \mathrm{m}^{2}\right), \mathrm{g}$ is gravitational acceleration $\left(9.8 \mathrm{~m} / \mathrm{sec}^{2}\right), \mathrm{m}$ is the mass, $\mathrm{L}$ is the two supports' separation distance, $\mathrm{S}$ is the deflection, $\mathrm{I}$ is the moment of inertia, $(\mathrm{m} / \mathrm{s})$ is the massdeflection slope, and $\mathrm{d}$ and $\mathrm{b}$ are the thickness and width of the sample, respectively. The samples were cut according to ANSI/ASTM-D790 (Figure- 3a).

\section{Impact strength test}

In the impact test, Charpy impact device was used, where the energy absorbed during rupture was determined, which refers to the material 's toughness. The impact strength test for the specimens was achieved by using the Charpy impact instrument INC. AMITYVILLE, New York. Pendulum of energy (5 Joul) was used in this test of the specimens. The tested samples were cut according to ISO179 standard fig. (3b). The impact strength (I.S) was determined from the following relation [18]:

\section{Tensile test}

$$
\text { Impact Strength }(I . S)=\frac{\text { Energy of fracture }(\mathrm{K} \mathrm{Joul})}{\text { Cross-sectional area }(\mathrm{m} 2)}
$$

After longitudinal fixing of the specimen by the upper and lower jaws of the equipment, a tensile load was applied at a rare of $5 \mathrm{KN}$ and velocity of $2 \mathrm{~mm} / \mathrm{min}$. By utilizing the connected graphic plotter (Model 1195, INSTRON) located in Al - Nu'man Factory /Ministry of Industry and Minerals, the relationship of $(\mathrm{P}-\Delta \mathrm{L})$ was obtained.

This relation was then modified to stress - strain $(\sigma-\varepsilon)$ relationship, which represents the main relation to obtain the ultimate tensile strength (UTS) and Young's modulus for the specimen under test. The samples were cut according to ASTM standard D638 (Figure-3c).

$$
\begin{aligned}
\sigma & =p / A \\
& \varepsilon=\Delta L / L
\end{aligned}
$$

where $P$ is the amount of applied force to the sample $(\mathrm{N})$, A is the cross sectional area of the sample (m2), and $\Delta \mathrm{L}$ is the elongation of the original length $(\mathrm{L})$ before the fracture occurs.

\section{Hardness test}

Hardness determines the surface penetration resistance of the measured material [20]. In this test, we used a manual device for hardness measurement, which is called measurement of durability. This device (shore D; xiuyan precision instrument factory, China) consists of spring for it apparent dibber from bore in substrate where be substrate emplaced interview for sample, and with cyclic shape Does the dibber with sample push by spring [21]. A shore hardness (scale D) instrument (model TH210) with an integrated probe (standard ISO 9001) was utilized. 


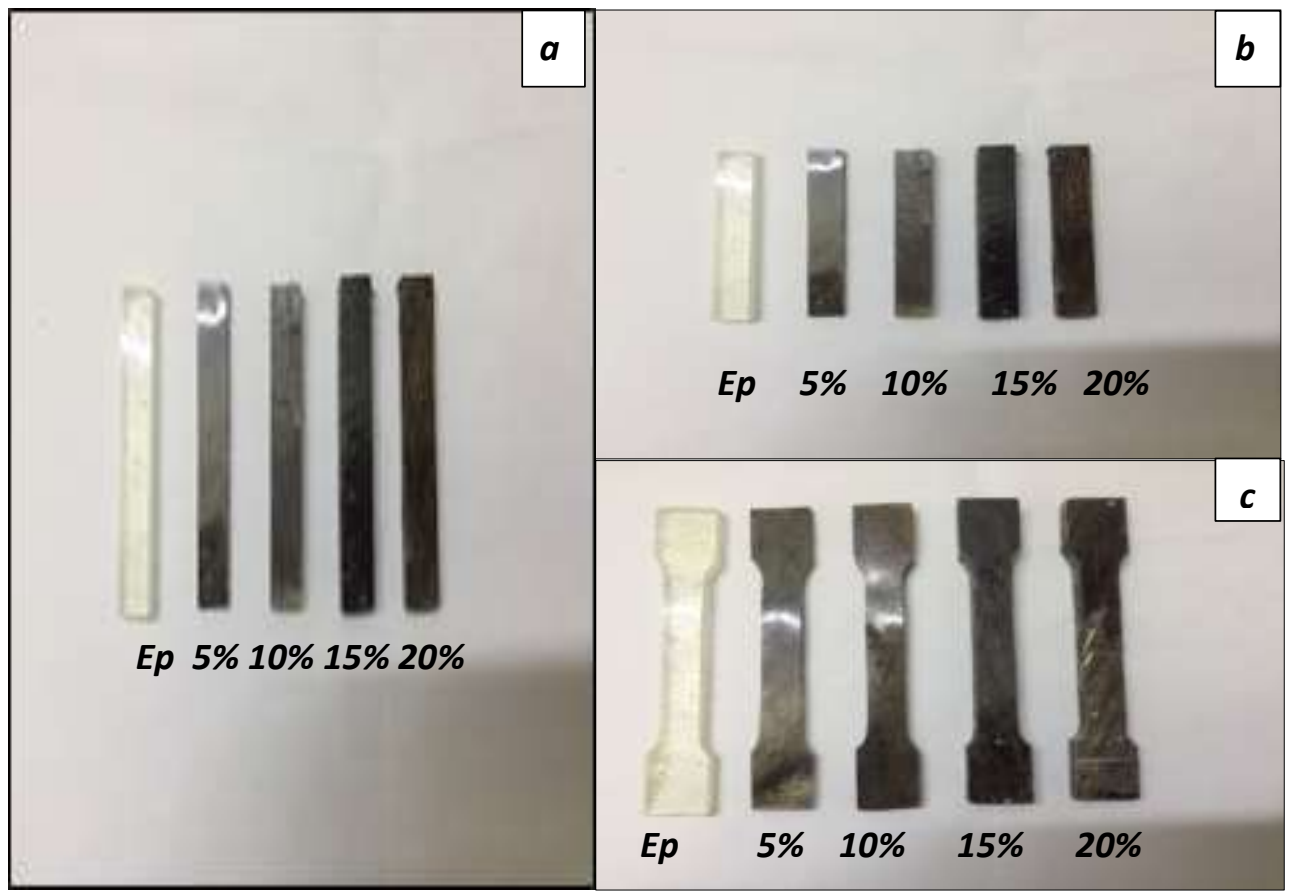

Figure 3-a-bending samples; b-impact samples; c-tensile samples

\section{RESULTS AND DISCUSSION}

\section{Three-point bending results}

The results of the test of bending property of the epoxy (EP) resin and the reinforcement (DPF / EP) composites with four weight percentages $(5 \%, 10 \%, 15 \%$ and $20 \%)$ are presented in Figures-4,5 which show the effects of load on the deflection of the samples. Young's modulus indicates the material's stiffness in the static bending condition. The tangential slope of the load-displacement curve was obtained from relation (1). Using the young's modulus, testing the composites demonstrated a linear behavior, as shown in Figure-4, There are many factors affecting the modulus of the composite, including the intrinsic properties of the materials or fillers, modulus, and the bonding force between the matrix and date palm fiber (that is responsible for the efficiency of load transfer in the composites), fiber distribution, aspect ratio, orientation of the fibers in the composite, and filler content [22]. The obtained results indicate an increase in modulus values of the composites as compared with that of the pure epoxy, which was directly proportional to the increase in the weight percentage of DPF. Applying load on the fibrous composites will distribute the resulting stresses on the matrix and the fibers, with the latter bearing the highest ratio of these stresses. Therefore, the value of Young's modulus increases [23] 


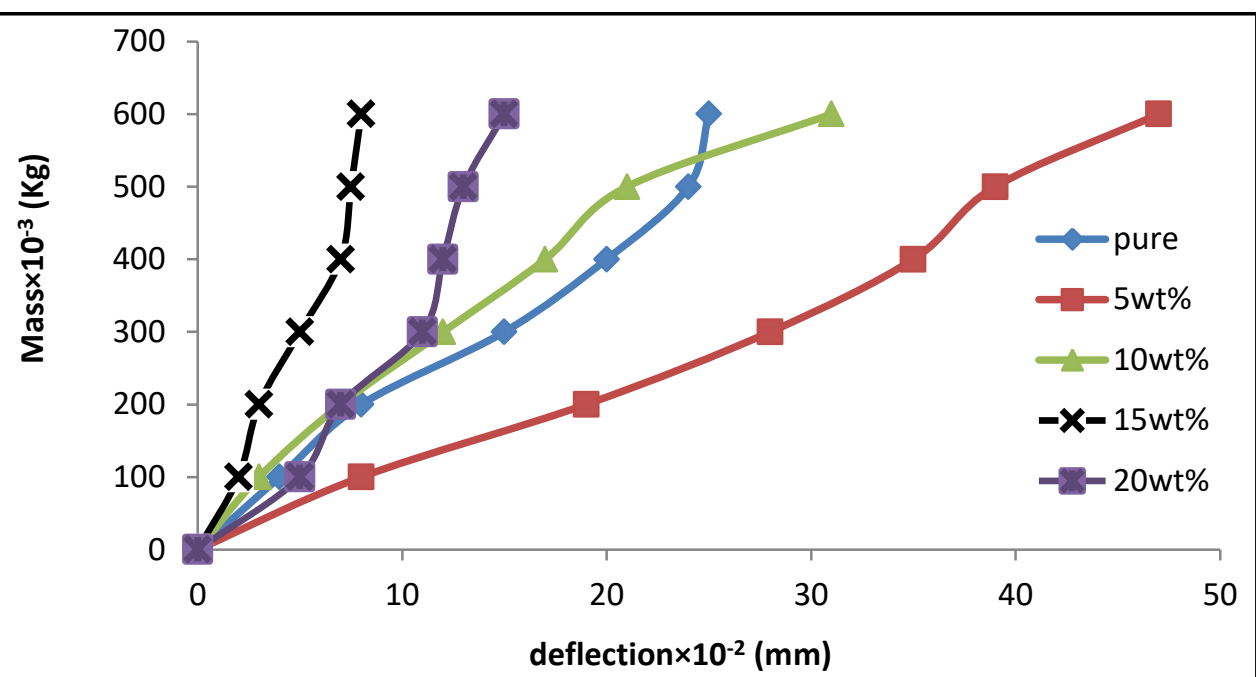

Figure 4-Relationship between mass and deflection of different percentages (EP, 5\%, 10\%, 15\% and $20 \%$ ) in the DPF/EP composites

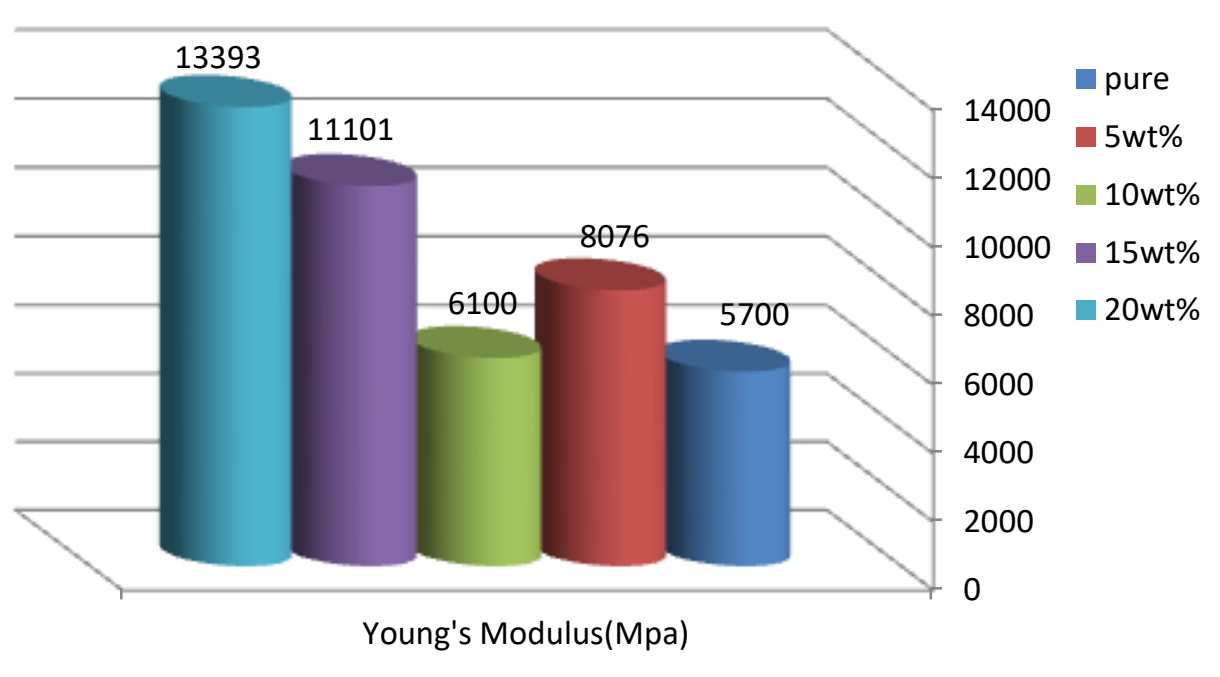

Figure 5-Comparison of Young's modulus values of various DPF/EP composites ( EP, 5\%,10\%,15\% and $20 \%$ ).

\section{Impact strength test results}

This test represents one of essential dynamic mechanical tests and is described as a very fast load that targets the sample which causes the final failure (fracture). The basic principle with which the impact test works is the absorption of the kinetic energy from the swinging hammer, as shown previously. The tested sample is supported at its side in a way that the fracture must take place in the middle of the piece. Part of the energy is absorbed from the sample while the remaining is responsible for the sample fracture. The fracture energy is the value used to determine the impact strength. Generally, the failure in the sample occurs due to the applied stress. Under dynamic quick stress, the material tends to behave as brittle rather than ductile [24, 25]. Therefore, the reinforcement effect on the prepared composite is to increase the energy required to break the sample under investigation. This energy is represented by the value of impact strength. Figure- 6 shows that all the samples of composites have high impact strength values as compared with that of the epoxy resin. This indicates that the fibers imparted the toughness of the composite as a result of the slowing down the cracks in the neighborhood of the fibers. The adhesion between the epoxy and fibers and the good dispersion improved the values of impact strength for the composites, which appears in the specimens shown in Figure-7. In this experiment, the toughening mechanism related to the fillers and crack deflection 
mechanisms may act with some elasticity of fibers, which increased the absorption energy and impeded crack propagation, resulting in a high impact strength.

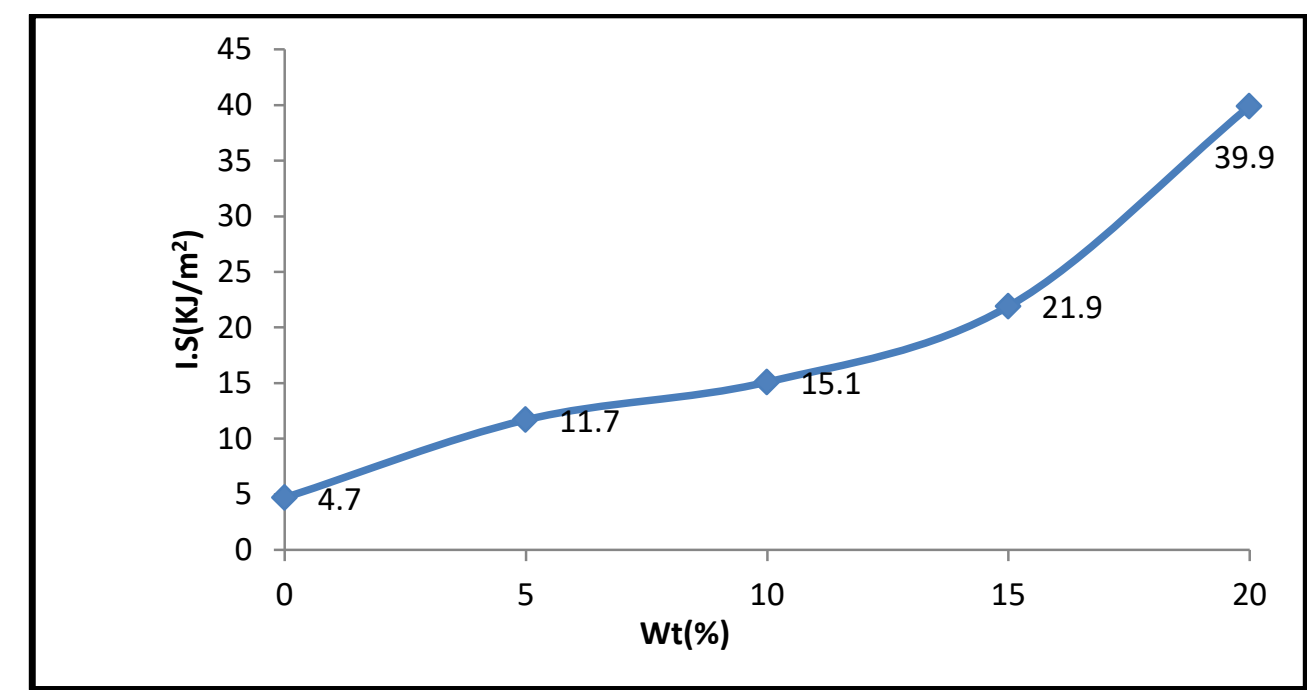

Figure 6-Comparison of impact strength values of various DPF/EP composites ( EP, 5\%,10\%,15\% and $20 \%$ ).

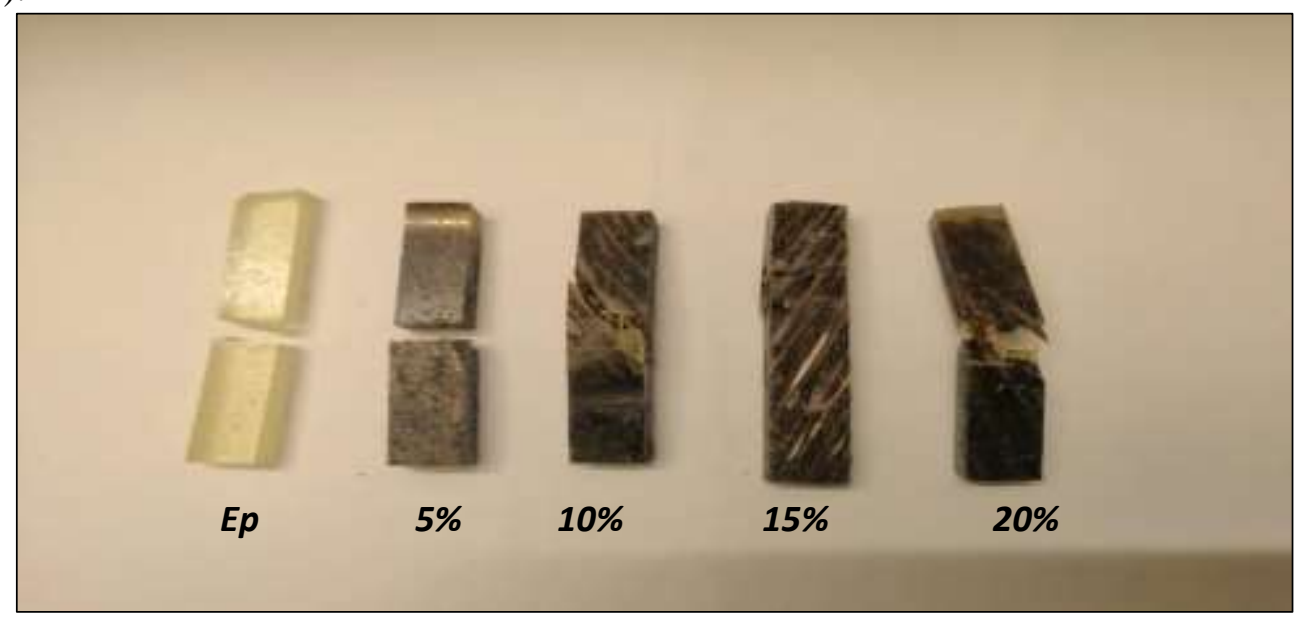

Figure 7-A photograph illustrating the impact strength values of the specimens after testing.

\section{Tensile test results}

Tensile characteristics are the most widely reported mechanical properties of any material. Tensile strength is the maximum load that the sample will carry before fracture happens under a slowly applied and gradually increased load during a tensile test [19].

An Instron device was used for this test, which was approved at a crosshead speed of $2 \mathrm{~mm} / \mathrm{min}$. Figure- 8 shows the curves for the DPF / EP composites with four weight percentages $(5 \%, 10 \%, 15 \%$ and 20\%). In general, it is known that epoxy is a hard and brittle material that fractures in a brittle mode. From the stress -strain curves of all composites, it is quite clear that those with weight percentages of 5\% and $10 \%$ DPF displayed an increased ultimate tensile strength (UTS) with a plastic deformation behavior, in spite of containing a high percentage of brittle material (EP). The evidence of these ductile behaviors is the occurrence of necking, followed by homogeneous drawing of the sample. This would lead to the conclusion that when the EP is mixed with $(5 \%$ and $10 \%$ of date palm fibers, its fracture mode will be changed from brittle to ductile, which means reducing the risks of brittle catastrophic failure during application. Imposing a ductility characteristic into the EP does not mean only changing the facture mode, but it also means increasing the toughness of such brittle matrix [26]. This would bring the composites to have a wider range of applications. While, with weight percentage of $15 \%$ and $20 \%$ DPF), a decrease in UTS was observed because of the incompatibility between the natural fibers and resin matrix. The stress concentration was accumulated at the weakness regions with 
the low adhesion forces between the matrix and the fibers. Tensile strength of the pure sample showed a higher value than that of the other samples. This result can be explained by the lack of adhesion between the matrix and fiber [27].

Generally, it is also accepted that the adhesion between the fiber and the matrix has a considerable influence on the mechanical properties of the fiber-reinforced polymer composites. Therefore, the interfacial bonding plays a main role in improving these properties, mainly the tensile strength of the composite, because it is affected by the efficiency of load transfer from the matrix to fiber via shearing at the interface [28]. The ultimate tensile strength states are demonstrated in Figures- $(9,10)$ represents photographic images of the fracture regions of DPF/EP fiber composites in all weight percentages .It can be seen that the specimens are fractured with significant changes in their cross-section areas, because date palm fibers are ductile materials.

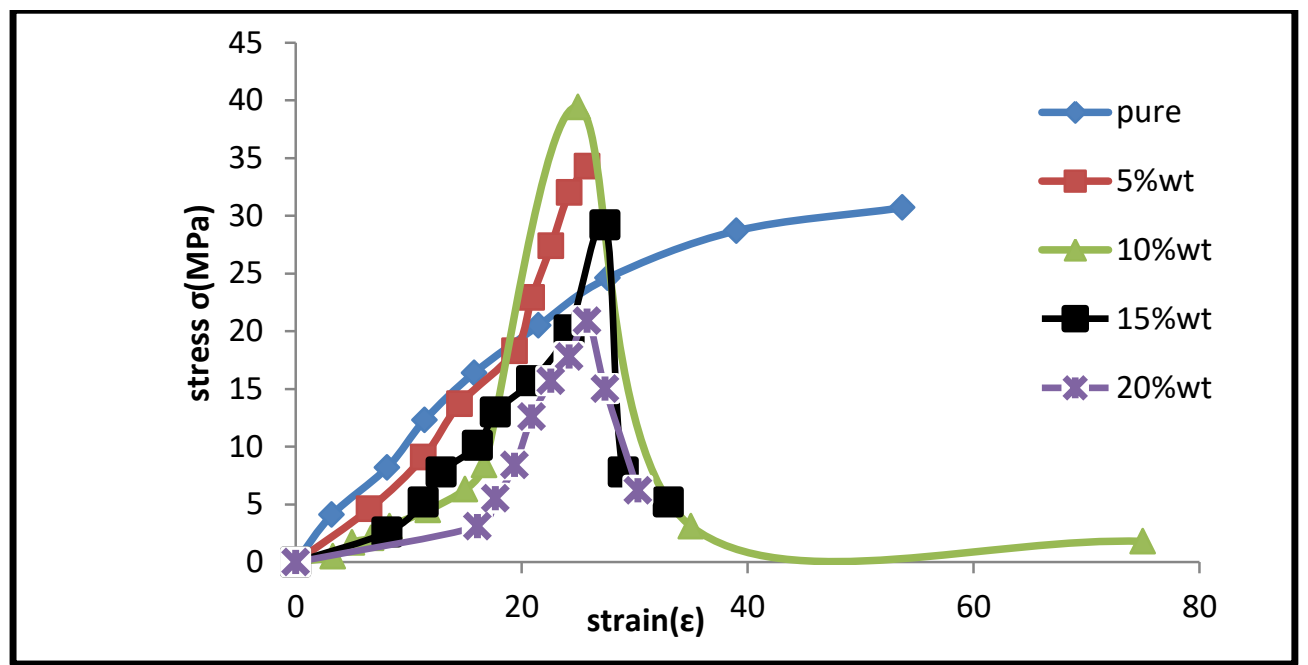

Figure 8- Stress-strain curves of composites reinforced with date palm fibers (DPF) with different weight percentages.

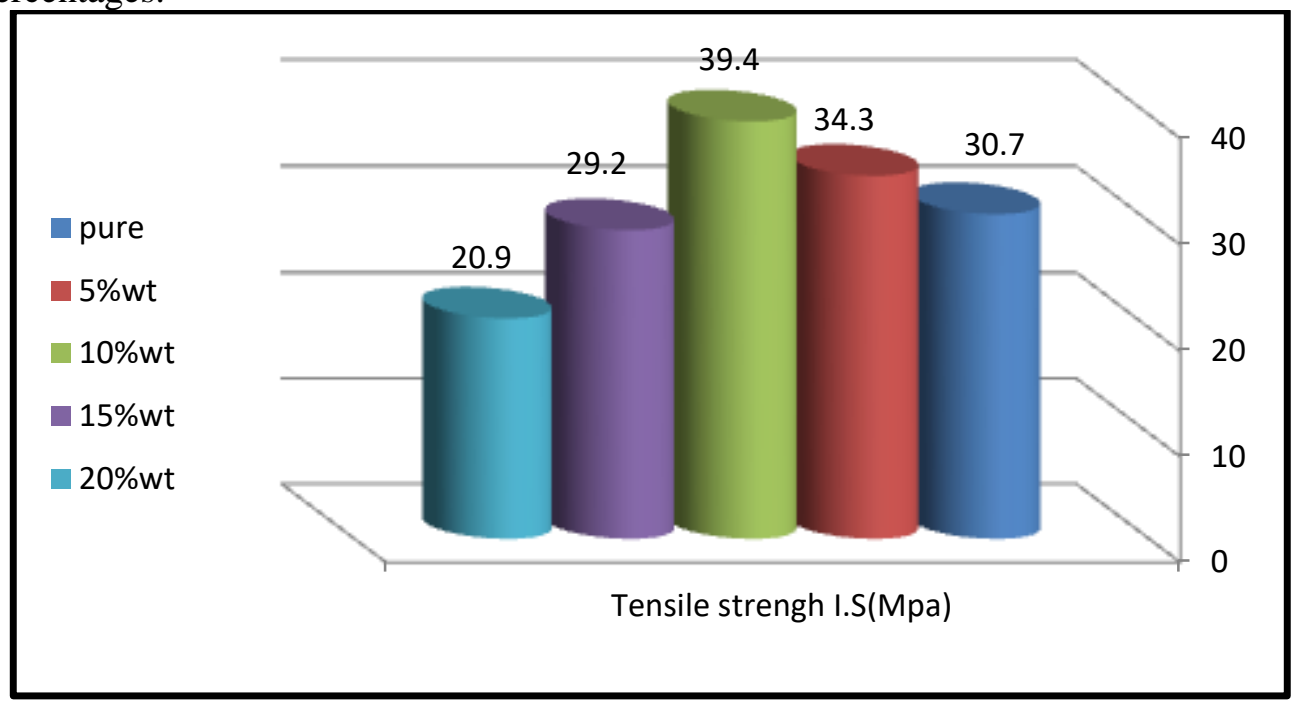

Figure 9-A comparison of ultimate tensile strength (UTS) values of DPF/EP composites ( EP, $5 \%, 10 \%, 15 \%$ and $20 \%)$. 


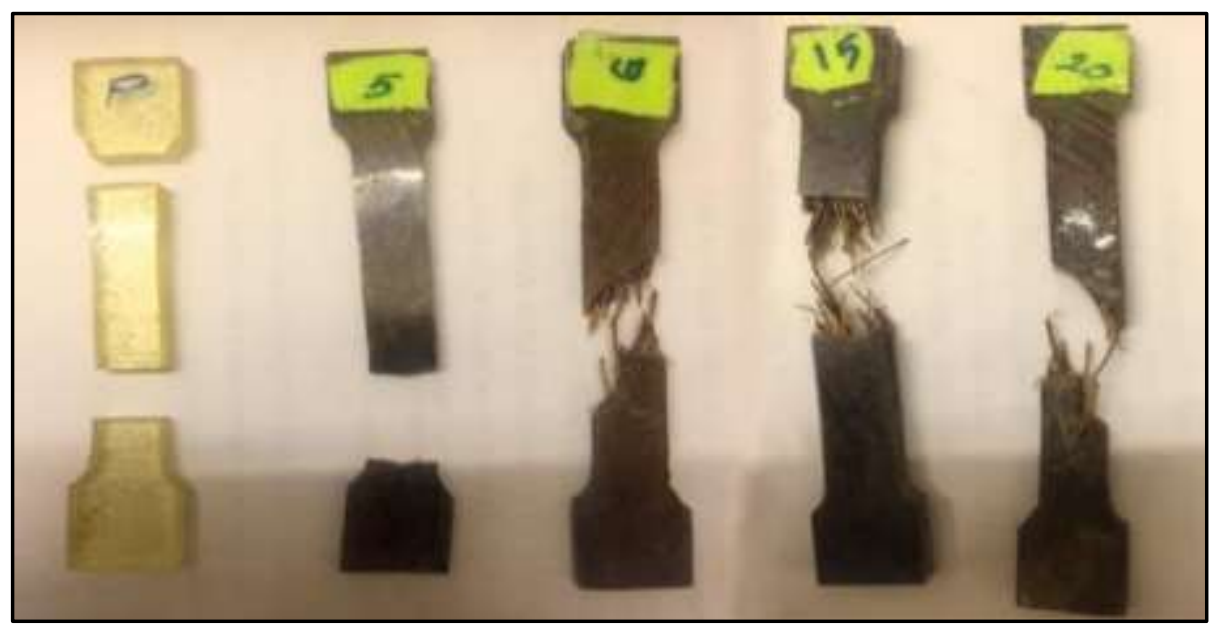

Figure 10-A photograph illustrating the tensile specimen .after testing

\section{Hardness test}

The measured hardness values of the composites are presented in Figure-11. The hardness of the composites was higher than that of the pure epoxy. This must be expected because as the filler enters the matrix, it shares the loading stress, resulting in more rigidity. It should be mentioned that surface hardness depends also on the bonding at the matrix and fiber interface. This result may be explained by the notion that the filler contributed to the hardness of the composite, since the movement of the matrix is restrained in the vicinity of each particle, and the stress is spread through the distributed fibers, thus enhancing composite hardness [29].Also, this increase in hardness is due to the strength of the polymer, which is the resistance of materials to plastic localized deformation of the surface. The hardness also links the relationship between fiber loading of the composite and modules [30].

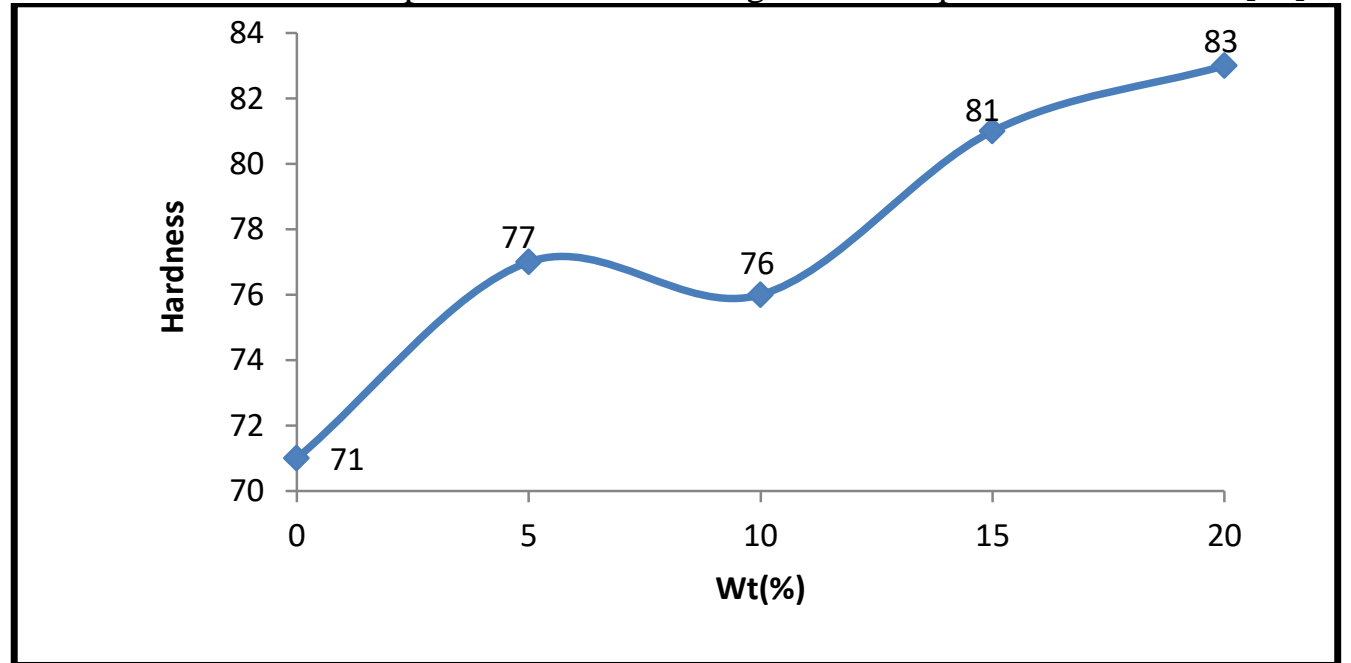

Figure 11-A comparison of hardness values of the DPF/EP composites ( EP, 5\%,10\%,15\% and 20\%).

\section{CONCLUSIONS}

Many research communities have stated that fibers such as sisal, hemp, flax and jute are ideal candidates in the improvement of polymers matrix composites. The date palm fibers are obtainable in many countries and were discovered to have numerous applications in several fields. According to experimental results presented in this work, the following conclusions can be drawn:

- In our research, we note that there was an increase in the values of Young's modulus, impact strength, and hardness by increasing the rate of reinforcement.

- In the case of tensile strength, the values were increased using reinforcements of $5 \%$ and $10 \%$ of DPF, but decreased using $15 \%$ and $20 \%$, due to weak link between the fiber and matrix. 


\section{REFRENCES}

1. Karthikeyan, S., Rajini N., Jawaid M., Winowlin Jappes JT., Thariq MTH., Suchart S. and Sukumaran, J. 2017 .A review on tribological properties of natural fiber based sustainable hybrid composits. J Engineering Tribology, 0(0)1-19.

2. Zeeshan, N. and Anshuman, S. 2019. Study on tribology of natural fiber reinforced polymer composites:A review ",SVOA Materials Science and Technology ,December 30: 410.https://sciencevolks.com/materials-science/.

3. Kumar, A. and Srivastava, A. 2017. Preparation and Mechanical Properties of Jute Fiber Reinforced Epoxy Composites. Industrial Engineering \& Management, 6: 234. doi:10.4172/21690316.1000234.

4. brahem .R. A. 2016. Influence of natural fillers on tribological and mechanical performance of polyester composites, Journal of the Egyptian society of tribology, 13(1): 43-53.

5. Hussein, S.M. and Rasheed, Z.N. 2019. Nano-reinforcement effect on PMMA denture base mechanical properties after immersing in different solution. Iraqi Journal of Science. Special Issue, pp.57-68. DOI: 10.24996/ijs.2019.S.I.10.

6. Abas, F.O. 2020. Re-Use of Date Palm Wastes to Improve Aging of Composite Concrete System. Iraqi Journal of Science, 61(3): 462-471. DOI: 10.24996/ijs.2020.61.3.1.

7. Ismail A. E. and Zamani. N. A. 2008.Tensile and impact behavior of hybrid extruded glass/natural fiber reinforced polypropylene composites. Tun Hussein University of Malaysia, International Conference on Environmental Research and Technology PP. (793-796).

8. Malkapuram, R., Kumar, V. and Negi. Y. S. 2009. Recent Development in Natural Fiber Reinforced polypropylene Composites, Journal of Reinforced Plastics and Composites, 28(10): 1169-1189.

9. Marais, S., Gouanve, F., Bonnesoeur, A., Grenet, J., Poncin- Epaillard, F., Morvan, C. and Me'tayer, M. 2005. Unsaturated polyester composites reinforced with flax fibers: effect of cold plasma and autoclave treatments on mechanical and permeation properties, Composites, 36: 975986.

10. Shamsi, M. and Mazloumzadeh, S.M. 2009. Some physical and mechanical properties of date palm trees related to cultural operations industry mechanization. Journal of Agricultural Technology, 5(1): 17-31.

11. Hosseinkhani, H., Euring, M. and Kharazipour, A. 2015. Utilization of date palm (Phoenix dactylifera L.) pruning residues as raw material for MDF manufacturing. Journal of Materials Science Research, 4(1): 46-62.

12. Marandi. S. M., bagheripour. M. H., Rahgozar. R. and Zare. H. 2008 .Strength and Ductility of randomly distributed Palm Fibers Reinforced Silty sand Soils. American Journal of Applied Science, 5(3): 209-220.

13. Nageswara, S, S. Lakshmi Narayanaz, M. Gangaraju, K. Reddi Prasad, SallaVenkataSubba Reddy .2018. Investigation of Mechanical Properties of Natural Fiber Reinforced Polymer Hybrid Composites, Lasted Journal for advanced research in applied sciences, 5(3), and ISSN. NO: 2394-8442.

14. Zaid, A. and Jimeniez, E.J.A. 1999.Date Palm Cultivation, FAO Plant Production and Protection",paper 165, ROMA (IT).

15. Mohanty, A.K., Misra, M. and Hinrichsen, G. 2000.Biofibres, biodegradable polymers and biocomposites: an overview, Macromol. Mater. Eng. 276/277, 1-24.

16. Hatnagar, M. S. B. "Eng. Mate. Tech.1998.3rd Butter worth Oxford,

17. Khurmi and Sedha R.S. 2008 .Materials Science S. Chand \& Company LTD.India.

18. Chawla K. K. 1987. Composite Materials (Science and Engineering), Springer -Verlag New York Inc.

19. Grawford. R. J. 1987. Plastics Engineering", 2nd edi., Pergamona Press, New York.

20. Diarmid. M., A. G. 2001. Angew. Chem Int. Ed. Engl., 40: 2581.

21. Sudad I. Younis, K. Oleiwi, Reem A. Mohammed .2018. Some Mechanical Properties of Polymer Matrix Composites Reinforced by Nano Silica Particles and Glass Fibers. Engineering and Technology Journal, 36, Part A(12),DOI: http://dx.doi.org/10.30684/etj.36.12A.10 
22. Sewench N. and Samah M. 2013. Characteristic of Hybrid Chestnut Shell Fillers/Epoxy Composite, Engineering and Technology Journal, 31(3): 368-380.

23. William D. and Callister Jr. 2000. Materials science and engineering. An introduction. John Wiley and Sons, Inc.U.S.A.

24. Ram, A. 1997. Fundamentals of polymer engineering. Plenum Press.

25. Brent, S. 2000. Plastic Materials and Processing.2nd, Brigham Young University.

26. Suspene .Land J. Pascault.1990. J. of Appl. Polym. Sci., 41: 2665 - 2675.

27. Raghad H. Mohammed, Mustafa A. Hassan and Noor S. Sadeq.2010. The edition effect of natural fiber on polymeric materials and study some thermal and mechanical properties. Journal of AlNahrain University, 13(1): 84-90.

28. Weigun.G, $\mathrm{Ph}$. D. thesis.1997. Interfacial Adhesion Evaluation of Uniaxial Fiber - Reinforced Polymer Composites by Vibration Damping of Cantilever Beam. Black Sburg, Virginia.

29. Samah M. 2013 .Improvement of Mechanical Properties for Electrical Conductive Polymer Composites. Journal of Al-Nahrain University, 16(4): 125-133

30. Seenaa I. Hussein, Nadia A.Ali, GhadaM.Saleh, Harith I.Jaffar.2019. Effect of Fiber (Glass, Poly Propylene) on Hardness, Water Absorption And Anti-Bacterial Activity of Coating Acrylic Polymer. Iraqi Journal of Science. Special Issue, pp: 1-6. DOI: 10.24996/ijs.2019.S.I.1. 